\title{
14 Construction of meaning and teacher control of learning
}

\author{
Nicolas Balacheff \\ CNRS \\ Laboratoire Leibniz-IMAG \\ Grenoble, France
}

\begin{abstract}
This paper focuses on students' construction of meaning and teacher control of learning in computer-based learning environments. The new complexity brought about by modern learning environments is discussed and illustrated from the point of view of learning and of teaching. The analysis presented is based on data gathered in the context of a distance tutoring scenario using the experimental platform TéléCabri-TéléCabri is a research action of the project Cabri-géomètre. The conclusion introduces two issues for further discussion: the type of knowledge teachers should have of the mathematics underlying the software they use, and the nature of the knowledge constructed by students in the course of their interactions with a learning environment.
\end{abstract}

\section{Keywords}

Distance learning, tele-teaching, geometry, direct manipulation, experimental, pedagogy.

\section{INTRODUCTION}

During the past decade, educational technology for mathematics has made a decisive step with the development of graphical interface, direct manipulation and symbolic computation. The trend is obviously that of a more friendly interface, a reification of mathematical objects and processes closer to what one may describe as a "What You Get Is What You Expect" (WYGIWYE) principle. In mathematics, Computer Algebra System (CAS) and Dynamic Geometry Software (DGS) have had the best benefit of these improvements. The time when complex 
programming languages were necessary in order to interact with the computer seems to be over; everything works nowadays as if one could directly perform actions on mathematical objects themselves. Even more, this access to mathematical artificial worlds is now possible through handheld calculators and not only through desktop computers. One would predict a new revolution.

But what about the last decade's revolution? A recent study reports that in France about $15 \%$ of the curricula had been modified as a result of taking into account the availability of handheld calculators, and that about $3 \%$ of the exercises proposed by teachers were specific to their use. As Cuban (1987) analysed, ten years ago, in a classical study of the use of 'machines' by teachers, "they will either resist or be indifferent to changes that they see as irrelevant to their practice, that increase their burdens without adding benefits to their student learning, or that weaken their control of the classroom" (p.71).

This issue of control is central when one considers teacher accountability with respect to the students learning outcomes. It is significant that researchers involved in the UK three-year Logo Maths Project, in the mid 80s, recognised the need for 'teacher-initiated activities' as a way to channel the students creativity and increase the probability of some specific learning outcome (Hoyles and Sutherland, 1989, 226-227). This recognition contrasts with the dominant trends of this period; it acknowledges that teachers are confronted with a paradoxical injunction: on one hand they must favour a free and genuine learner construction of meaning, but on the other hand they need to be in good command of the learning outcome as "mediators of society's goals" (Bishop, 1993, p.238).

I will here focus on these two aspects and their interactions: students construction of meaning and teacher control of learning in the context of the use of computer-based learning environments.

\section{CONSTRUCTING MEANING IN AN ARTIFICIAL WORLD}

Drawing upon an analysis of the nature of the above mentioned software packages, as well as considerable experience in their use in classrooms, provides evidence that the WYGIWYE principle is satisfied provided that the user has enough mathematical knowledge to be able to read the screen in a proper way.

Hillel (1993) provides us with a good example, in the case of CAS, when he shows that students need "new skills to cull pertinent information about a function" (p.40), what he refers to as "a certain art to graphical "window shopping" (ibid.). For the student, the issue at stake is to focus on "the idea of invariance of functions as opposed to properties which are artefact of scaling, such as flatness or steepness of graphs" (ibid.).

Such examples can be found in the research studies which have questioned the development of students' conceptions as a result of their interaction with a learning environment; in algebra (Sutherland, 1993) as well as in geometry (Laborde, 1993; Hölzl, 1996). 
One could paraphrase Dreyfus $(1993, \mathrm{p} .125)$ and state that it is not pure perception that makes artificial mathematical world meaningful to the mathematics student but the interpretation of the perceived images in terms of mathematical structures or relationships.

But even such a mathematical reading must be cautious and must take into account an unavoidable computational transposition of knowledge as a result of its implementation in a computer (Balacheff and Sutherland, 1994).

Because of its hardware characteristics and software idiosyncrasy, the computer introduces a new semiotic for mathematics. This is especially evident in the case of the use of graphical representations of functions or of geometrical objects. The dynamics of these representations as well as the way the discrete characteristics of the screen are taken into account are likely to have an effect on the objects behaviours.

If one accepts the constructivist hypothesis, which states that learning results from a process of adaptation of the learner to his or her environment, these semiotic characteristics are likely to have an effect on mathematical meanings. Then, what will be the consequences on learning as a result of interactions with the computer? Some learners may construct meanings different from what is expected by mathematics teachers. How could that be diagnosed and remedied by teachers?

\section{MAKING SENSE OF THE STUDENT UNDERSTANDING}

\section{Distance tutoring as a window on the teacher-student interaction}

The complexity of the task of the teacher in using new computer-based learning environments becomes especially evident in the context of modern distance tutoring environments. In such environments, the constraints of the one-to-one communication between a teacher and a student sharing a common workspace make visible the work of the teacher trying to make sense of the student's understanding and to cope with the mathematical specificities of the computerbased learning environment. As one teacher working in such a setting, interviewed by Lesh and Kelly (1997), indicated: "Before I did this one-to-one tutoring I never really had much time to see all the 'unusual' ways my kids think about the problems I assigned." (p.410).

In engaging in a personalised interaction with a student, the possibility that the teacher is likely to ignore what this student says or does is considerably reduced, whereas in the classroom there is always a possibility to shift the attention to another student whose contribution is easier to exploit. Distance tutoring opens a window on the teacher-student dialogue through which one may get a better view on the way the teacher manages the interaction with the learner. 


\section{Distance tutoring with TéléCabri}

The ideas described in the previous section provided the focus the experimental studies and analysis we carried out within the research project TéléCabri. The TéléCabri experimental platform allows both the teacher and the learner to share Cabri-géometre at a distance, and to discuss one another's ideas through a videochanel included in the screen of the computer.

The outlines of the teacher's task are: to be available for any student call, to identify the mathematical domain and questions (which are in general not the ones the student states), to diagnose problems, to support the learning and to provide the student with suggestions for further activities. The basic scenario of the use of TéléCabri at the Grenoble Academic Hospital alternates phases of student autonomous work (in the ward or at home) and, at will, phases of interactions at a distance with a teacher. The students also visits of the teacher on a regular basis - the technological platform is conceived of as complementary to the regular teacher interventions.

\section{Facts, phenomena and modelling}

Let us consider the problem given in figure 1 :

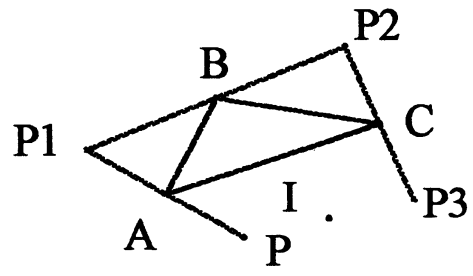

Construct a triangle $A B C$. Construct a point $P$ and its symmetrical point P1 about $A$. Construct the symmetrical point $P 2$ of $P$ about $B$, construct the symmetrical point $P 3$ of $P$ about C. Move $P$. What can be said about the figure when P3 and $P$ are coincident? Construct the point I, the midpoint of [PP3]. What can be said about the point I when $P$ is moved? Explain.

\section{Figure 1}

The figure being constructed with Cabri-géomètre, the direct manipulation of the point $P$ shows an obvious fact: the point I does not move. Since I depends directly on $\mathrm{P}$ and $\mathrm{P}$, two points which move when one moves $\mathrm{P}$, this fact seems surprising. The central purpose of the activity is to propose an explanation.

Let us examine the interaction between a teacher and a student, Fabien, about this problem (a more detailed analysis can be found in Balacheff and SouryLavergne, 1995). Fabien has observed the fact but he has no insight about the reason: "The point I does not move, but so what?..." Since Fabien has noticed spontaneously the parallelogram $A B C I$, the tutor encourages him to focus on itthe student proves that $\mathrm{ABCI}$ is a parallelogram. At this stage, from the point of 
view of geometry (and of the tutor), the reason why I stands immobile while $P$ moves, is obvious. The tutor then provides Fabien with several hints:

Hey! What does is mean that when one moves $P, I$ does not move? It tells you that I is how? [prot.113]

... you have used a lot of intermediate points but if we consider the conclusion that they don't play any role any more, the points $P, P 1, P 2$, P3. [prot.117]

But if it does not move when you move P. That tells you what? I, the point I, you have told me that it moved according to which points? [prot.139]

The others, they do not move. You see what I mean? Then how could you define the point I, finally, without using the points $P, P 1, P 2, P 3$ ? [prot.143.]

But Fabien still does not see the 'obviousness', it is only later in the interaction that the tutor tells him the mathematical reasons of the immobility of $I$, provoking a genuine ha-ha! effect ...

Actually, Fabien failed to relate the fact that $\mathrm{ABCI}$ is a parallelogram to the fact that the location of I does not depend on P, P1, P2 and P3. In order to explain the immobility of $I$, the teacher had to obtain from the student the construction of a link between a mechanical world -which is that of the interface of Cabrigéomètre, and a theoretical world-which is the world of geometry. Only this link can turn the observed fact of the immobility of I into a phenomenon, that is the property of the invariance of $I$. The tutor's interventions follow a kind of Socratic strategy under the constraints of a didactical contract which functioned as a paradoxical injunction: the more precisely the tutor would tell to Fabien what he had to do, the more she risked provoking the disappearance of the expected learning.

Then, sharing the screen as a common field experimentation, the student and the teacher may share facts, but not phenomena. Simply said, it is not enough to look at the screen of the DGS to see the geometry.

Let us listen to an other student, Sébatien [prot. 78-84]:

Sébatien: "What can be said about the point I when $P$ is moved? Explain" So, hmm... I move $P$ and I does not move.

Tutor: $\mathrm{Hm}$, yes!

Sébatien: So... I have said... But is not very clear... That when, for example, we put $P$ to the left, then $P 3$ compensate to the right. If it goes up, then the other goes down...

Tutor: So what...

Sébatien: But I have not found a mathematical proof, $\mathrm{hmm}$

Tutor: $O K$, so what can you say about I. That... why I is invariant? Why I does not move?

Sébatien: It is exactly what I have not found... How to prove that ... in fact P3... it annuls the move of $P$. 
This excerpt from Sébastien's protocol gives even more explicit evidence that the passage from the mechanical world to the world of geometry is not obvious. It is a process of modelling.

\section{Making sense of the student's production}

At the beginning of a new interaction, in the context of distance teaching, the tutor has very little information on what the student has produced. Nevertheless, it is important that she is able to quickly make a diagnosis, and one which is as reliable as possible, in order to take the best decisions to support further learning. But, just looking at the screen may not be sufficient in order to get the needed information. In particular, in the case of DGSs, what is displayed on the screen is a drawing for which meaning depends no only on the actual set of significant pixels but also on the way it behaves when dragging its basic points (Laborde, 1993, pp55-57).

For example, in the context of Cabri-géomètre, a circle drawn using as a centre a point $O$ and passing through a point $P$, will not differ at first sight from the drawing of a circle defined by a centre $O$ and a radius on which is drawn a point $P$ (as a 'point on object').

Let us come back to the interaction of Fabien and his tutor. The following short excerpt [prot. 326-343] illustrates well the point I want to raise (the interaction evolves around the diagram given in figure 2):

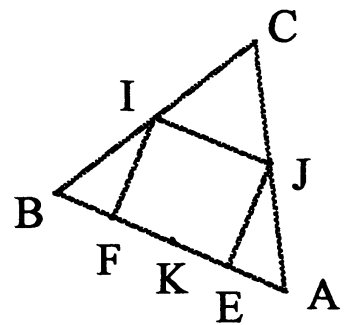

Figure 2

Tutor: Now, then, where are you?

Fabien: It's done, I have drawn the isosceles triangle.

Tutor: OK. So now, your triangle, it stays always isocelous?

Fabien: Yes.

Tutor: Do we make a little verification? Wait, This point ... I cannot move it, why? So, it is visible that it's more or less correct. Look, I will try to move the point $C$, just to see. Hey! Why the point $B$ follows when $I$ move the point $C$. That's strange!

Fabien: Sorry?

Tutor: The point $C$... 
Fabien: Yes?

Tutor: ... When I move the point $C$, the point $B$ follows and the point $A$ doesn't move. How did you do it?

Fabien: Yes, because it is a circle.

Tutor: It's on a circle...

Fabien: That's it, $C$ is the centre of the circle...

Tutor: Yes...

Fabien: and $B$ and $A$ are on the circle.

Tutor: Hmm, OK. B, you linked it to the circle? How did you do that?

Fabien: No, no. $C$ is the centre of the circle.

Tutor: $C$ is the centre, but your point $B$ ?

Fabien: Wait, I will show you.

Finally, Fabien and the tutor used the Cabri-géomètre functionalities which enabled them to see the hidden objects in order to clarify the construction.

This example is typical of the problems encountered by teachers when, in order to make sense of the student production, they need information about the process which has led to it. The complexity of this process and the large variety of the possibilities make this task harder than in the classical paper-and-pencil environments.

It requires a knowledge of the software which cannot be reduced to knowing the user's manual or even its original specifications.

\section{REVISITING THE COMPLEXITY OF THE TEACHER CONTROL OF LEARNING}

In a domain other than geometry, the teaching of fractions, Ohlsson (1991) gives us a very clear example of a widely shared belief among computer-scientists or software designers. He describes a software package for the learning of fractions which provides the student with two different windows, one window displays fractions (mathematical register) and this is associated with another one which displays a related illustrations world (concrete world of partitioning strips). Ohlsson claims that "[this] yoking feature enabled [the student] to get mathematical feedback on her physical actions", but he also reports that a student could nevertheless achieve a "wrong insight" and so he raises the following questions (among several others): "Why did the student construct one idea rather than another? Would it have been possible to predict before the event that this exercise would produce this particular insight?" (p.55).

These questions are crucial to the teacher control of learning. Ohlsson searches for an answer in the direction of learning theories, I suggest here that one may get a better understanding of this complexity by looking at the mathematical characteristics of both the environment and the learning situations since modern learning theories emphasise, although in different ways, the 
centrality of the process of adaptation of the learner to his or her environment. The characteristics of this environment are then crucial in the construction of meaning and thus to explore them from the point of view of the conceptualisations they may stimulate is as essential as exploring the possible learner cognitive processes. The outcome of the latter depends largely on the characteristics of the former.

Distance tutoring opens a new window on the teacher-student interaction, in that it provides further evidence of the complexity of teaching and the way teachers may cope with this complexity. Two directions of research are suggested which are likely to be essential for both distance teaching and teaching in classrooms using computer-based technology:

- the development of teacher training in order to improve the teacher understanding of the mathematics of the computer. Computer-based learning environments raise an intrinsic difficulty as compared to classical material environments due to the dynamic representation they display as well as their autonomy in performing actions. These features are likely to change the relationships between the learner and the symbolic environment, but it is also the case between the teacher and his or her working environment. In the case of geometry, Laborde (1993) emphasised that the teacher may well benefit from knowing what mathematics underlies the software he or she will use in her classroom. On the same line, I would now question the relationships between mathematics and the computer-based artificial world, suggesting that 'Modelling' may be the keyword for a possible answer. If it is so, one may consider this relationships as being part of the mathematical content to be taught just as Laborde suggested was the case in the distinction between drawing and figure that DGS has placed at the forefront of the geometrical scene.

- A key issue for the teacher is to keep control of the learning situation while leaving to the student enough autonomy so that genuine learning processes can develop. The richness and the complexity of the outcome of the interaction between the learner and the machine is such that the teacher will find difficult to make sense of the student's production in all cases. This issue is especially important in the case of distance tutoring because of time constraints, and calls for the development of machines capable of interacting with teachers in order to facilitate their activity, in particular at the level of interpreting and debugging students' productions.

The new directions constitute a challenge for the current research in $\mathrm{AI}$ and education, with a shift from autonomous artificial tutors to machine as teaching partners. 
Note

The project TéléCabri is part of the project Cabri-géomètre from the Leibniz Laboratory. The experimental studies to which I refer have involved JeanFrançois Bonneville, Nathalie Masseux, Sophie Soury-Lavergne and Lucile Vadcard.

\section{REFERENCES}

Balacheff, N. and Soury-Lavergne S. (1995). Analyse du rôle de l'enseignant dans une situation de préceptorat à distance: TéléCabri. In R. Noirfalise and M-J. Perrin-Glorian (eds.) Actes de la VII Ecole d'été de didactique des mathématiques, IREM de Clermont-Ferrand, 47-56.

Balacheff, N. and Sutherland R. (1994). Epistemological domain of validity of microworlds, the case of Logo and Cabri-géomètre. In R. Lewis and P. Mendelshon (eds.) Proceedings of the IFIP TC3/WG3.3: Lessons from learning. Amsterdam: North-Holland, 137-150.

Bishop, A. (1993). On determining new goals for mathematical education. In C. Keitel and K. Ruthven (eds.) Learning from computers: mathematics education and technology. Berlin: Springer-Verlag, 222-242.

Cuban, L. (1986). Teachers and machines: the classroom use of technology since 1920. New York, NY: Teachers College Press.

Dreyfus, T. (1993). Didactic design of computer-based learning environments. In C. Keitel and K. Ruthven (eds.) Learning from computers: mathematics education and technology. Berlin: Springer-Verlag, 101-130.

Hillel, J. (1993). Computer-Algebra systems as cognitive technologies: Implication for the practice of mathematics education. In C. Keitel and $\mathrm{K}$. Ruthven (eds.) Learning from computers: mathematics education and technology. Berlin: Springer-Verlag, $18-47$.

Hölzl, R. (1996). How does 'dragging' affect the learning of geometry? International Journal of Computers for Mathematical Learning 1(2), 169168

Hoyles, C. and Sutherland, R. (1989) Logo mathematics in the classroom. London: Routledge.

Laborde, C. (1993). The computer as part of the learning environment: the case of geometry. In C. Keitel and $\mathrm{K}$. Ruthven (eds.) Learning from computers: mathematics education and technology. Berlin: Springer-Verlag, 48-67.

Lesh, R. and Kelly, A. E. (1997). Teachers' evolving conception of one-to-one tutoring: a three-tiered teaching experiment. Journal for Research in Mathematics Education 28(40), 398-430.

Ohlsson, S. (1991). Knowledge requirements for teaching: the case of fractions. In P. Goodyeart (ed.) Teaching knowledge and intelligent tutoring. Norwood, NJ: Ablex Publishing Corporation, 25-59. 
Sutherland, R. (1993) Connecting theory and practice: results from the teaching of Logo. Educational Studies in Mathematics 24, 95-113.

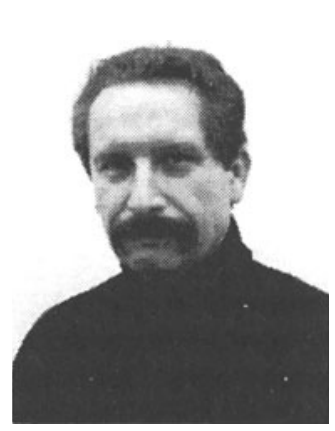

Nicholas Balacheff is Research Director at the French Centre National de la Recherche Scientifique (CNRS) since 1988. He graduated at the University Joseph Fourier, in Grenoble, where he got its first thesis in 1978 and his thèse d'état in 1988 . His preceding position where at the ENSIMAG (1972-1988) and at the Laboratoire IRPEACS in Lyon (1988-1992). Presently he is a member of the Laboratoire Leibniz-IMAG, where he chairs the EIAH team (Computer-based Environments and Human Learning). His field of research is mathematics education with a special interest for computer-based learning environments. 